\title{
Topical alpha-selective p38 MAP kinase inhibition reduces acute skin inflammation in guinea pig
}

This article was published in the following Dove Press journal:

Journal of Inflammation Research

5 February 2010

Number of times this article has been viewed

\author{
Satyanarayana Medicherla \\ Jing Ying $M a$ \\ Mamtha Reddy \\ Irina Esikova \\ Irene Kerr \\ Fabiola Movius \\ Linda S Higgins \\ Andrew A Protter
}

Scios Inc, Fremont, CA, USA

Correspondence: Satyanarayana

Medicherla

Schering Plough Biopharma,

90I California Ave, Palo Alto,

CA 94304, USA

Tel + I 650496 I 255

Email satya.medicherla@spcorp.com

\begin{abstract}
Certain skin pathologies, including psoriasis, are thought to be immune-mediated inflammatory diseases. Available literature clearly indicates the involvement of inflammatory cells (neutrophils, T cells, and macrophages), their cytokines, and the p38 mitogen-activated protein kinase (MAPK) signaling pathway in the pathophysiology of psoriasis. Neutrophils play an important role in the formation of acute inflammatory changes in psoriasis. Acute inflammation or acute flares in psoriasis remain poorly addressed in clinical medicine. In this communication, we first establish a simple and reproducible model for studying neutrophil-mediated acute skin inflammation. Using the hairless guinea pig, due to the similarity of skin architecture to that of human, acute inflammation was induced with an intradermal injection of $50 \mu \mathrm{g} / \mathrm{mL}$ lipopolysaccharide (LPS) in $50 \mu \mathrm{L}$ solution. Myeloperoxidase (MPO) activity was measured by MPO-positive neutrophils and shown to increase for 24-hours post-injection. Simultaneously, the level of phosphorylated p38 MAPK was documented for 48-hours post-LPS injection in the skin. Next, we used this model to examine the therapeutic potential of an $\alpha$-selective $\mathrm{p} 38$ MAPK inhibitor, SCIO- 469. A comparison of topical application of SCIO-469 at $5 \mathrm{mg} / \mathrm{mL}$ or $15 \mathrm{mg} / \mathrm{mL}$ to vehicle revealed that SCIO-469 dose-dependently reduces acute skin inflammation and that this effect is statistically significant at the higher dose. Further examination of tissues that received this dose also revealed statistically significant reduction of MPO activity, phosphorylated p38 MAPK, interleukin-6, and cyclooxygenase- 2 . These data suggest that the $\alpha$-selective p38 MAPK inhibitor, SCIO-469, acts as a topical anti-inflammatory agent via the p38 MAPK pathway to reduce neutrophil induced acute inflammation in the skin. These observations suggest that $\alpha$-selective p38 MAPK inhibition may be an effective therapeutic strategy to manage acute skin inflammation
\end{abstract}

Keywords: SCIO-469, skin, neutrophils, myeloperoxidase, phosphorylated p38, topical

\section{Introduction}

Immune-mediated inflammation is thought to underlie certain skin diseases, including psoriasis. ${ }^{1,2}$ Psoriatic patients have increased numbers of circulating neutrophils, which also appear early in the formation of new lesions Historical data clearly suggests involvement of inflammatory cells (neutrophils, T cells, and macrophages) and their cytokines tumor necrosis factor-alpha (TNF $\alpha$ ), interleukin (IL)-1 $\beta$, IL-6, IL-8 and cycloxygenase-2 (COX-2) in the initiation, development and maintenance of the psoriatic lesions as well as in induction of acute flares. ${ }^{3-5}$ Neutrophils play an important role in the formation of the acute inflammatory changes in psoriasis, while chronic inflammation is well explained by a $\mathrm{T}$ cell-associated inflammationsustaining loop. ${ }^{6}$ Treatment of acute inflammation or acute flares in psoriasis is an unmet medical need..$^{4,5,7,8}$ The p38 mitogen-activated protein kinase (MAPK) signaling submit your manuscript $\mid$ www.dovepress.com

Dovepress 
pathway is active in inflammatory skin diseases ${ }^{9-11}$ and inhibitors of this pathway reduce skin inflammation in various rodent models of human skin diseases. ${ }^{12,13}$ SCIO-469 is a p38 MAPK inhibitor which has been tested clinically as an oral agent in several patient populations, but has not yet been tested in humans using topical application. A major roadblock in the identification and development of topical treatments for psoriasis is the structural dissimilarity of rodent and human skin. In guinea pigs and humans, the thickness of stratum corneum and epidermis is similar and there is a very good correlation of in vivo transdermal drug delivery between these two species. ${ }^{14}$ Further, erythema and edema during skin inflammation are highly similar for these two species. An intermittent exudate of fluid and of leukocytes, both neutrophils and lymphocytes, are seen in the epidermis in early psoriasis. This early histology has been reconfirmed several times with neutrophil presence and basal keratinocyte changes in psoriatic patients. ${ }^{15}$ Hence, neutrophils infiltration as measured by myeloperoxidase (MPO) activity was used to assess the effect of p38 MPAK inhibition on acute skin inflammation in guinea pigs.

In the first part of the present communication, we describe a guinea pig model of acute skin inflammation that is driven by the activation of the p38 MAPK signaling pathway. Lipopolysaccharide (LPS) was used as an inducer of acute skin inflammation. LPS is known to activate p38 MAPK signaling ${ }^{14,16,17}$ and initiates infiltration by inflammatory cells, especially neutrophils, ${ }^{18}$ into the skin and promotes a cascade of events that includes the release of cytokines, ${ }^{19}$ protease activation, ${ }^{20}$ free radical generation, ${ }^{20}$ and skin apoptosis. ${ }^{21}$ After pilot studies examining the dose-response effects of intradermal LPS (derived from Salmonella typhimurium) at doses of $0,25,50$ and $100 \mu \mathrm{g}$ in a volume of $50 \mu \mathrm{L}$ vehicle for a period of 48-hours, we chose the $50 \mu \mathrm{g} / \mathrm{mL}$ dose of LPS for subsequent testing, as this dose caused a significant amount of phosphorylation of p38 and infiltration of neutrophils into the skin by 24 -hours.

In the second part of the present communication, this model was used to examine the therapeutic potential of SCIO-469 in topical application in its base form. SCIO-469 is a small molecule $\alpha$-selective p38 MAPK inhibitor that is structurally similar to SD-282 or/and SD-169, and has been tested in oral formulations in clinical studies for other inflammatory conditions. ${ }^{22}$ No toxicities have been reported with SCIO-469 in animal models. ${ }^{23-25}$ Both SD-282 and SD-169 have been previously shown to inhibit inflammatory infiltration and cytokine release in various animal models of inflammatory diseases..$^{24,25}$

\section{Materials and methods \\ SClO-469 chemical structure, potency, and specificity}

SCIO-469 is an orally active indole-5-carboxamide, ATPcompetitive inhibitor of p38 kinase. The half maximum inhibitory concentration $\left(\mathrm{IC}_{50}\right)$ of SCIO-469 for human $\mathrm{p} 38$ MAPKs $\alpha, \beta, \gamma$, and $\delta$ isoforms were determined in duplicate using ELISA assays adapted from published methods. ${ }^{26}$ Purified human recombinant (Escherichia coli) p38 MAPK isoforms were incubated with substrate (Myelin Basic Protein [MBP], $10.75 \mu \mathrm{g} / \mathrm{mL}$ ) in the presence of inhibitor or control in a buffer comprised of $50 \mathrm{mM}$ Hepes, $20 \mathrm{mM} \mathrm{MgCl}$, $0.2 \mathrm{mM} \mathrm{Na}_{3} \mathrm{VO}_{4}, 1 \mathrm{mM}$ DTT, pH 7.4 for 60 minutes at $25^{\circ} \mathrm{C}$. The readout was ELISA quantitation of incorporation of ATP into MBP (MDS Pharma, Tampa, FL USA). Enzyme concentrations were as follows: $75 \mathrm{ng} / \mathrm{mL}$ for $\mathrm{p} 38 \alpha ; 250 \mathrm{ng} / \mathrm{mL}$ for $\mathrm{p} 38 \beta$, $\mathrm{p} 38 \gamma$, and $\mathrm{p} 38 \delta$. The adenosine triphosphate (ATP) concentration was previously optimized for each assay and was $100 \mu \mathrm{M}$ in the $\mathrm{p} 38 \alpha$ assay, $10 \mu \mathrm{M}$ in the $\mathrm{p} 38 \beta$ assay, $1 \mu \mathrm{M}$ in the $\mathrm{p} 38 \gamma$ assay, and $3 \mu \mathrm{M}$ in the p38 $\delta$ assay. The control for the $\alpha$ and $\beta$ isoforms was SB 202190 and for the $\gamma$ and $\delta$ isoforms the control was staurosporine. The $\mathrm{IC}_{50}$ values of SCIO-469 revealed a 10-fold selectivity for $\mathrm{p} 38 \alpha$ MAPK $\left(\mathrm{IC}_{50}\right.$ value of $\left.0.01 \mu \mathrm{M}\right)$ compared to $\mathrm{p} 38 \beta$ MAPK $\left(\mathrm{IC}_{50}\right.$ value of $\left.0.1 \mu \mathrm{M}\right)$, whereas inhibition of $\mathrm{p} 38 \gamma$ MAPK and $\mathrm{p} 38 \delta$ MAPK was less than $50 \%$, even at concentrations of $10 \mu \mathrm{M}$. When tested in vitro at a concentration of $10 \mu \mathrm{M}$, SCIO-469 demonstrated no inhibitory activity against a panel of other kinases including ERK2, JNK-1, and MAPKAPK-2. In addition, SCIO-469 demonstrates no effect on the activity of purified COX-1 or COX-2 enzymes.

\section{Animals}

All experiments were carried out according to protocols approved by the Institutional Animal Care Committee of SCIOS, Inc. (Fremont, CA USA). Thirty guinea pigs were housed in accordance with the National Institute of Health guidelines in micro-isolator filter cages and maintained on a 12-hour light/dark cycle with free access to food and water. Upon study initiation, guinea pigs were individually housed in solid bottomed cages with Alpha Dry bedding.

\section{Guinea pig model of LPS-induced, neutrophil-, and p38 MAPK-driven skin inflammation}

The entire back of the thirty guinea pigs was washed gently from the dorsal scapular area to the dorsal lumbo-sacral area 
with alcohol wipes, rinsed with $0.9 \%$ saline and allowed to dry. Each guinea pig was injected (26 gauge needle $/ 1.0 \mathrm{~mL}$ glasses Hamilton micro syringe) with LPS at a dose of $50 \mu \mathrm{g} / \mathrm{mL}$ in a $50-\mu \mathrm{L}$ volume of saline into the skin. The injection site was marked with a Shur/Mark marker (Triangle Biomedical Sciences, Durham, NC). The marker was used to place a line from the injection site across the bleb to show the histologist the direction of injection. Thirty guinea pigs were divided into six groups each consisting of five guinea pigs and they were sacrificed at 2-, 4-, 6-, 8-, 24-, and 48-hour time points, respectively. Skin was bisected from the LPS injected dot, which was marked by black dye. Skin punch biopsies were saved for immunohistochemical (IHC) analysis of MPO, a marker for neutrophil infiltration into the skin, and for phosphorylated p38 MAPK (pp38). The tissue was fixed with 10\% formalin, processed and paraffin embedded on edge. Total neutrophils (labelled with MPO) infiltrated in derma were automatically counted throughout the inflammatory area (six fields) under $20 \times$ magnification with the aid of Image Pro Plus (Media Cybernetics, Silver Spring, MD USA).

\section{IHC staining protocol for myeloperoxidase (MPO) activity}

The primary antibody (Rabbit MPO Ab-1) was obtained from Lab Vision Corp (formerly Neo Markers; Fremont, CA USA), and secondary antibody (Goat Anti-Rabbit Biotinlated IgG) from Chemicon International, Inc. (Temecula, CA USA). Negative control antibody (Normal Rabbit IgG) was purchased from Santa Cruz Biotechnology (Santa Cruz, CA USA). Based on the intensity, distribution and number of the positively stained neutrophils, a score was assigned as 0 for none, 1 for mild, 2 for moderate, 3 for strong, 4 for severe, and 5 for robust.

IHC staining protocol for phosphorylated p38 MAPK Rabbit anti-phospho-p38, which is a polyclonal IgG antibody, was purchased from Cell Signalling Technologies (Danvers, MA USA). Secondary antibody, goat anti-rabbit biotinlated IgG, was obtained from Chemicon International, Inc. Normal rabbit IgG from Santa Cruz Biotechnology was used in the negative control. Based on the intensity, distribution and number of the positively stained cells, a score was assigned with 0 for none, 1 for mild, 2 for moderate, and 3 for severe.

\section{Test of the effect of topical SClO-469 on skin inflammation}

We first conducted a dose-response study with SCIO-469. SCIO-469 free base in 20\% isopropanol and 80\% propylene. The ethyl glycol-400 (IPA-PEG-400) was prepared in two concentrations, $5 \mathrm{mg} / \mathrm{mL}$ and $15 \mathrm{mg} / \mathrm{mL}$. The entire backs of thirty guinea pigs were washed gently from the dorsal scapular area to the dorsal lumbo-sacral areas with alcohol wipes, rinsed with $0.9 \%$ saline and dried. Each guinea pig received a single intraderma injection of $50 \mu \mathrm{g}$ LPS in $50 \mu \mathrm{L}$ vehicle at the dorsal midline close to the scapular region. Soon after the injection, animals were randomized into three treatment groups each consisting of 10 guinea pigs. With an aid of a Hill Top Chamber (Hill Top Research, Miamiville, OH USA), Groups 1, 2, and 3 received topical IPA-PEG-400 (vehicle), SCIO-469 at $5 \mathrm{mg} / \mathrm{mL}$ and SCIO-469 at $15 \mathrm{mg} / \mathrm{mL}$, respectively. Briefly, a Hilltop chamber was filled with the respective solutions and placed on the injection site of the skin for continuous topical administration. The chamber was affixed with a piece of 1 -inch waterproof veterinary surgical tape. The animals were monitored periodically throughout the day by an associate scientist to prevent the removal of the surgical tape and the Hilltop chamber. The wrap was removed 8-hours after its placement and the Hilltop chamber was refilled and reapplied with the respective solutions. In addition, to prevent removal overnight, the chambers were secured by wrapping a piece of 3-inch Coban Self-Adherent Wrap around the guinea pig's torso and back. The animals were returned to their cages and observed for behavioral signs of discomfort or pain. Care was taken to wrap securely but still loosely enough to avoid irritation. Animals were closely observed during the 24-hour study period except between the hours of 7 PM to 7 AM. All observations and adjustments with respect to the secured state of the Hilltop chambers and pain/distress were recorded. Guinea pigs were euthanized 24-hours after the initiation of the study and skin punch biopsies were saved for hematoxylin and eosin (H\&E) analysis, for skin inflammation at a gross level and microscopic level (IHC for MPO). The IHC analysis for MPO was conduced as described above.

\section{Analysis of phosphorylated p38 MAPK, IL-6, and COX-2}

Using skin punch biopsies, IHC analysis of pp38 was conducted as described above. Goat anti-mouse IL-6 from R\&D System (Minneapolis, MN USA) was used as a primary antibody. Donkey anti-Goat biotinlated IgG was used as a secondary antibody (Chemicon International, Inc). For a negative control, normal goat $\mathrm{IgG}$ was purchased from Santa Cruz Biotechnology. COX-2 primary antibody was purchased from Alexis Biochemicals (San Diego, CA). The secondary antibody, goat anti-rabbit biotinylated $\mathrm{IgG}$, was purchased from Chemicon International, Inc. The negative antibody was rabbit IgG which was purchased from Santa Cruz Biotechnology. Based on the intensity, distribution and 
number of the positively stained neutrophils, endothelial cells and macrophages a score was assigned as

$$
\begin{aligned}
& \text { None }=0 \\
& 100 \text { to } 299 \text { MPO positive cells } / \text { field }=1 \\
& 300 \text { to } 399 \text { MPO positive cells } / \text { field }=2 \\
& 400 \text { to } 499 \mathrm{MPO} \text { positive cells } / \text { field }=3 \\
& 500 \text { to } 599 \text { MPO positive cells } / \text { field }=4 \\
& >600 \text { MPO positive cells } / \text { field }=5 .
\end{aligned}
$$

\section{Statistical analysis}

Analyses were carried out using Graph Pad statistical analysis software (San Diego, CA USA). Comparative data sets whose differences reached a level of significance of $P<0.05$ were defined as statistically significant.

\section{Results}

\section{LPS induces a neutrophil- and p38 MAPK- driven skin inflammation in guinea pigs}

Administration of LPS induced dose- and time-dependent increases in phosphorylation of p38 MAPK and infiltration of neutrophils was measured by MPO activity (data not shown). The maximum effect on neutrophils was observed at a dose of $50 \mu \mathrm{g} / \mathrm{mL}$ at 24-hours time point. There was no observable phosphorylation or infiltration of neutrophils in the vehicle control at 8-, 24-, and 48-hour time points which suggests that there is no needle effect.

LPS intradermal injection at a dose of $50 \mu \mathrm{g}$ in a $50 \mu \mathrm{L}$ volume induced a neutrophil-mediated skin inflammation that increased monotonically over time, beginning at 6-hours post-injection and reaching a maximum level by 24-hours. LPS induced elevation of neutrophil infiltration was statistically significant by 6-hours $(P<0.005)$ when compared to the 2-hour time point. The increase remains statistically significant at 8-, 24-, and 48-hours $(P<0.01, P<0.001$ and $P<0.001$, respectively) (Figure 1A). Phosphorylated p38 MAPK was observable in neutrophils and endothelial cells beginning at 8-hours post-injection and continued for 48-hours (Figure 1B). The increases in pp38 are statistically significant at 8-, 24-, and 48-hour time points where $P$ values were $<0.05,<0.01$, and $<0.001$, respectively, when compared to the two-hour time point. Neutrophils infiltration increased for 24-hours post-injection, with phosphorylated p38 MAPK levels continuing to rise for at least another 24-hours thereafter. A maximal response was obtained 24-hours after dosing with $50 \mu \mathrm{g} / \mathrm{mL}$ LPS/site.

We chose the $50 \mu \mathrm{g} / \mathrm{mL}$ dose for subsequent studies. This dose caused significant increase in phosphorylated p38 MAPK and infiltration of neutrophils into the skin by 24-hours when compared to the vehicle control, allowing study of the acute therapeutic effect of SCIO-469. For practical purposes, the short duration of the study minimizes the time required for securing the Hilltop chambers.

\section{Topical SCIO-469 reduces skin inflammation in guinea pig}

Topical administration of SCIO-469 dose-dependently reduced skin inflammation as observed grossly (Figure 2A), and at a cellular level, where neutrophil infiltration as measured by MPO activity was reduced (Figure 2B). The effects are statistically significant at the higher dose SCIO-469 $(15 \mathrm{mg} / \mathrm{mL} ; P<0.001)$ when compared to the vehicle group. Immunohistochemical studies reveal that SCIO-469 at the higher dose significantly reduced IL-6 expression in neutrophils and endothelial cells (Figure 3, upper panel; $P<0.001)$ and reduced COX-2 expression in neutrophils, endothelial cells, macrophages and fibroblasts (Figure 3, middle panel; $P<0.001$ ). Further, SCIO-469 at the higher dose significantly reduced pp38 MAPK in neutrophils and endothelial cells (Figure 3, lower panel; $P<0.01$ ).

\section{Discussion}

In the present study, we established a model system for studying neutrophil-mediated acute skin inflammation and its sequelae, for testing potential topical therapies. The model is simple and reproducible (Medicherla unpublished observations, 2005), involving induction with LPS. $50 \mu \mathrm{g} / \mathrm{mL}$ LPS were gauged to maximally induce neutrophils at 24-hours post-injection, with phosphorylated p38 MAPK levels continuing to rise for at least another 24-hours thereafter. This dose and time was used in designing the current studies of the therapeutic potential of topical administration of $\alpha$-selective p38 inhibitor, SCIO-469.

We undertook to examine the therapeutic potential of SCIO-469 in topical application in its base form in 20\% isopropanol alcohol and 80\% propylene ethyl glycol-400 (IPA-PEG-400). A comparison of SCIO-469 at $5 \mathrm{mg} / \mathrm{mL}$ or $15 \mathrm{mg} / \mathrm{mL}$ versus vehicle revealed that only the higher dose gave a statistically significant improvement of inflammation over vehicle treatment. Further examination of tissues that had received this dose revealed statistically significant reduction of neutrophils $(P<0.001)$, pp38 MAPK $(P<0.0001)$, IL-6 $(P<0.05)$, and COX-2 $(P<0.001)$ whereas the lower did not.

Neutrophils play an important role in the formation of acute inflammatory changes in psoriasis, while 


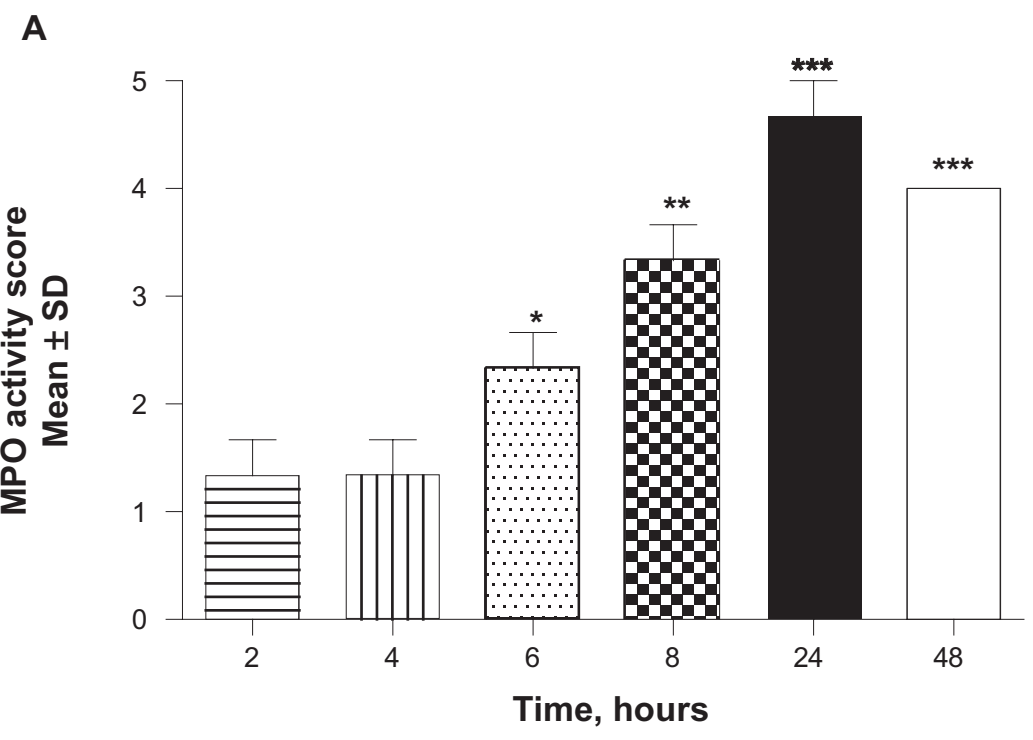

B

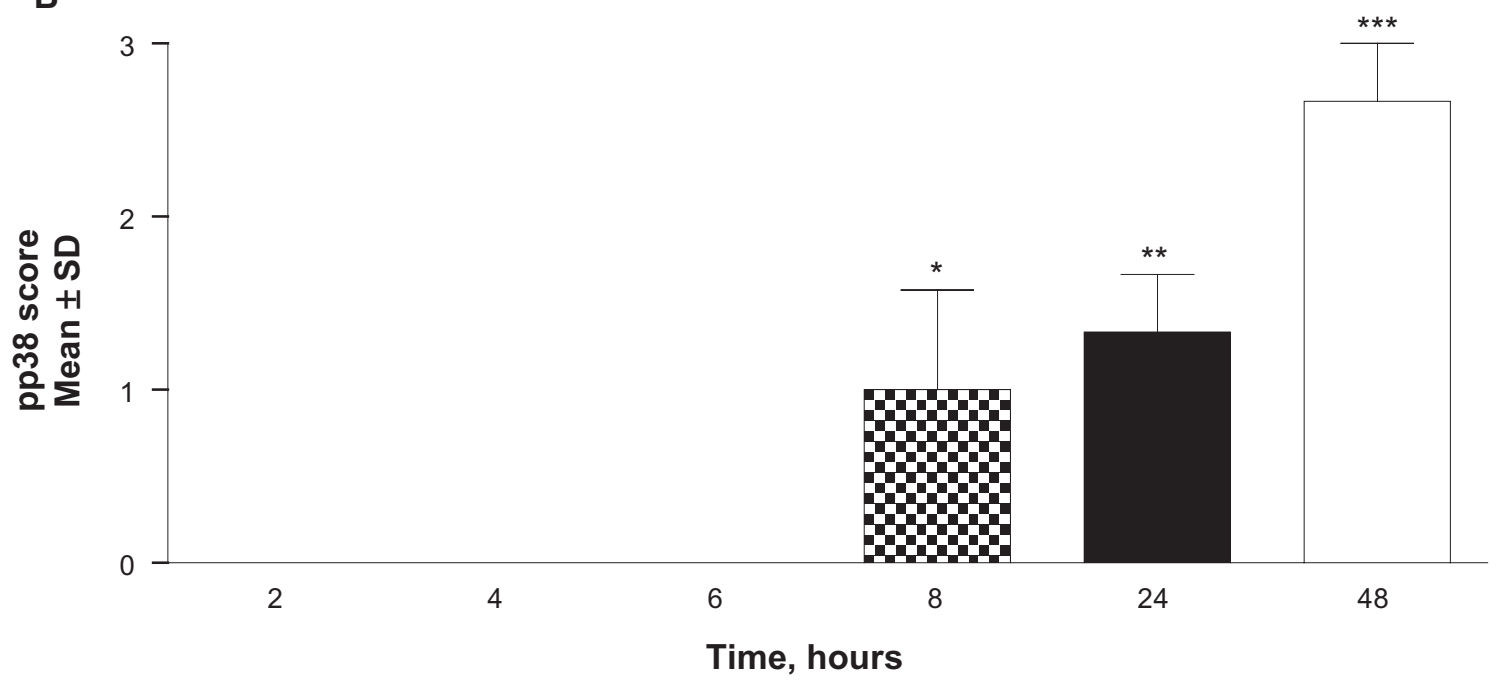

Figure I Time-dependent infiltration of neutrophils and phosphorylation of p38 in the skin. A dose of $50 \mu \mathrm{g} / \mathrm{mL} \mathrm{LPS}$ in a $50 \mu \mathrm{L}$ injection volume induced neutrophil-mediated skin inflammation as measured by MPO activity increased monotonically over time, beginning at 6-hours post-injection and reaching a maximum level by 24 -hours when compared to the two-hour time point $(\mathbf{A} ; * P<0.05 ; * P<0.005 ; * * * P<0.00 I)$. Phosphorylated $\mathrm{p} 38$ MAPK was observable in neutrophils and endothelial cells beginning at 8 -hours post-injection and continued for 48-hours $(\mathbf{B} ; * \mathrm{P}<0.05$; **P $<0.0 \mathrm{I}$; $* * * \mathrm{P}<0.00 \mathrm{I}$ compared to two-hour time point). Values are reported as the mean $\pm \mathrm{SD} ; \mathrm{n}=10$. Abbreviations: LPS, lipopolysaccharide; MAPK, mitogen-activated protein kinase; MPO, myeloperoxidase; PP38, phosphorylated p38; SD, standard deviation.

chronic inflammation in psoriasis is well explained by a T cell-associated inflammation-sustaining loop. ${ }^{6}$ Patients with moderate to severe psoriasis experience significant deterioration in quality of life. ${ }^{27}$ Acute flares can evolve into a more severe disease due to enhanced neutrophil cytotoxicity. ${ }^{28}$ Currently, management of acute flares in psoriasis are a clinical challenge. It is evident from the present study that SCIO469 significantly reduces acute neutrophil infiltration into the skin, which suggests it is capable of effecting at least one key element in formation of acute inflammatory changes in psoriatic flares. Further, in psoriatic patients with acute flares, there is a diminished axon-reflex function due to a down regulation of C-fiber neuronal firing. ${ }^{29} \mathrm{SD}-282$, which is a structural and functional analogue of SCIO-469, and which has recently been shown to reduce the firing or release of calcitonin generelated peptide from these nerve endings. ${ }^{30}$ Intriguingly, no side effect was seen at topical dose $(50 \mu \mathrm{g} / \mathrm{mL})$ used in this study or when given at a dose of $15 \mathrm{mg} / \mathrm{kg} /$ oral in guinea pigs (unpublished) or $30 \mathrm{mg} / \mathrm{kg} /$ oral in rats. ${ }^{22}$ Together, these observations suggest that an $\alpha$-selective p38 inhibitor may be a promising therapeutic approach to reduce neutrophil mediated acute flares in psoriasis.

Available literature also indicates a pattern in formation of acute flares in psoriatic patients in which stress and other 
A

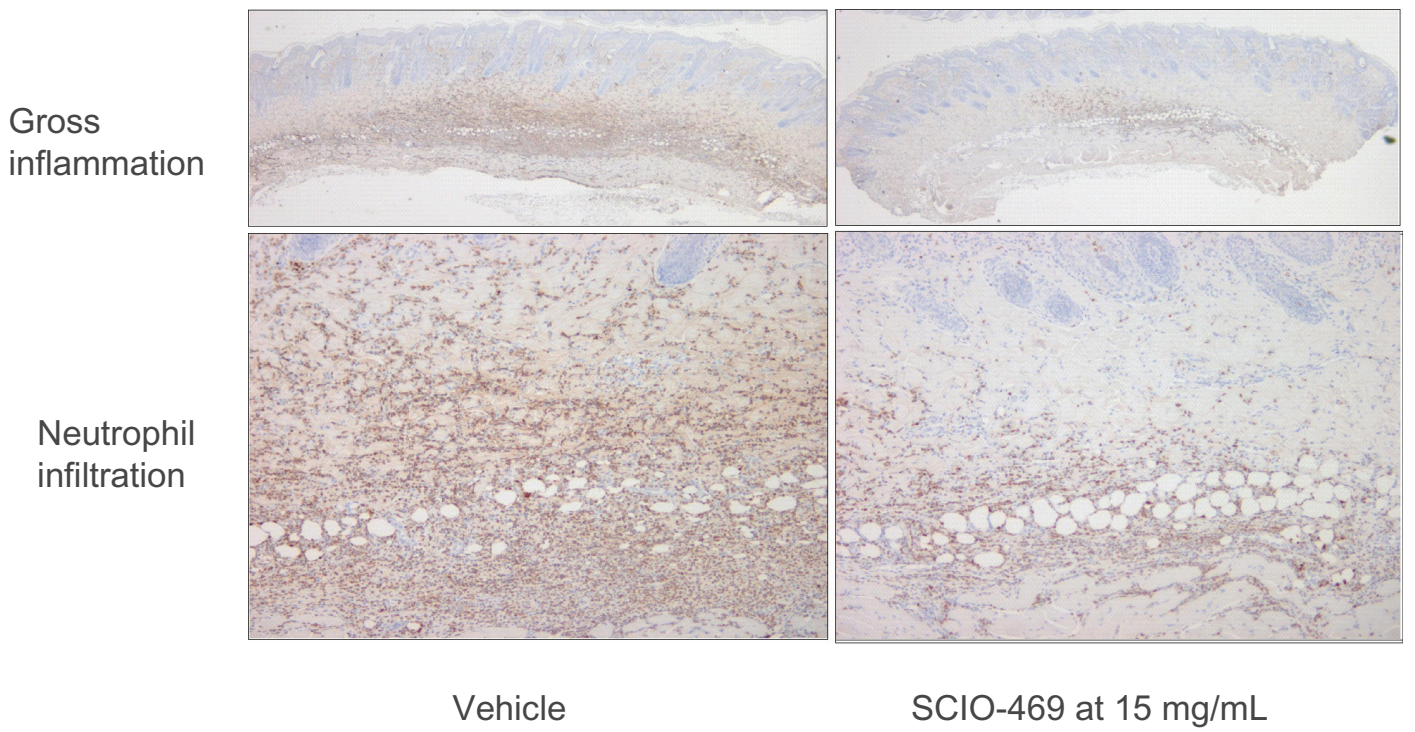

B

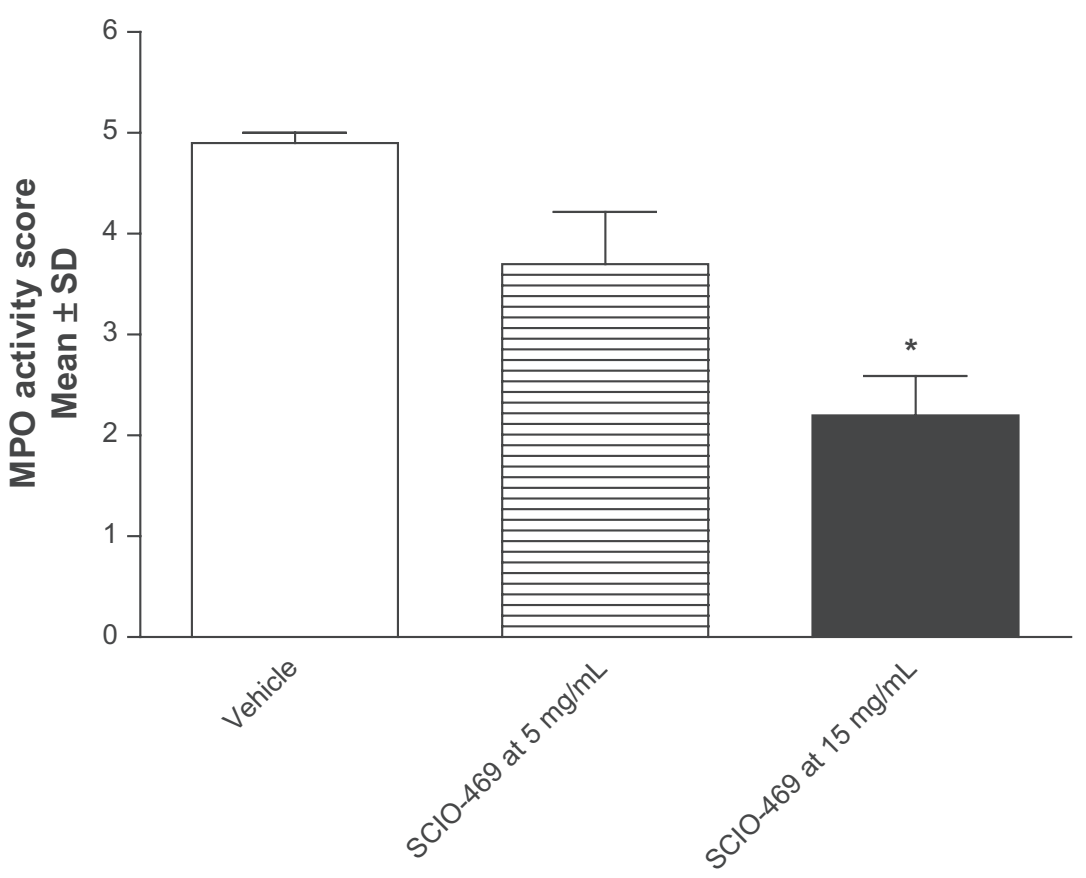

Figure 2 SCIO-469 dose-dependently reduces neutrophil-derived skin inflammation. SCIO-469 dose-dependently reduced skin inflammation in gross observation. Left panel from vehicle group and right panel from topical SCIO-469 at $15 \mathrm{mg} / \mathrm{mL} ; \mathbf{A}$ ) and neutrophil driven inflammation as measured by MPO activity B). Data are statistically significant at high dose $(15 \mathrm{mg} / \mathrm{mL} ; * P<0.00 I)$.Values are reported as the mean $\pm S D ; n=10,40 / 200 \times$ (upper/lower). Figure $2 A$ is at $40 / 200 \times$ magnification.

Abbreviations: MPO, myeloperoxidase; SD, standard deviation.

conditions play a major role, ${ }^{4,5,7,8}$ and p38 MAPK signaling is upregulated in stressful states. ${ }^{31}$ This opens a modality to manage these acute flares in a prophylactic manner based on psoriatic patients' episodic clinical history. ${ }^{7}$ Similar to its therapeutic application, a prophylactic application of an $\alpha$-selective p38 MAPK inhibitor may be of value in the prevention of acute flares for psoriasis patients.

We conclude that topical administration of $\alpha$-selective p38 MAPK inhibitor SCIO-469 acts as an anti-inflammatory agent via inhibition of the p38 MAPK signalling pathway to 

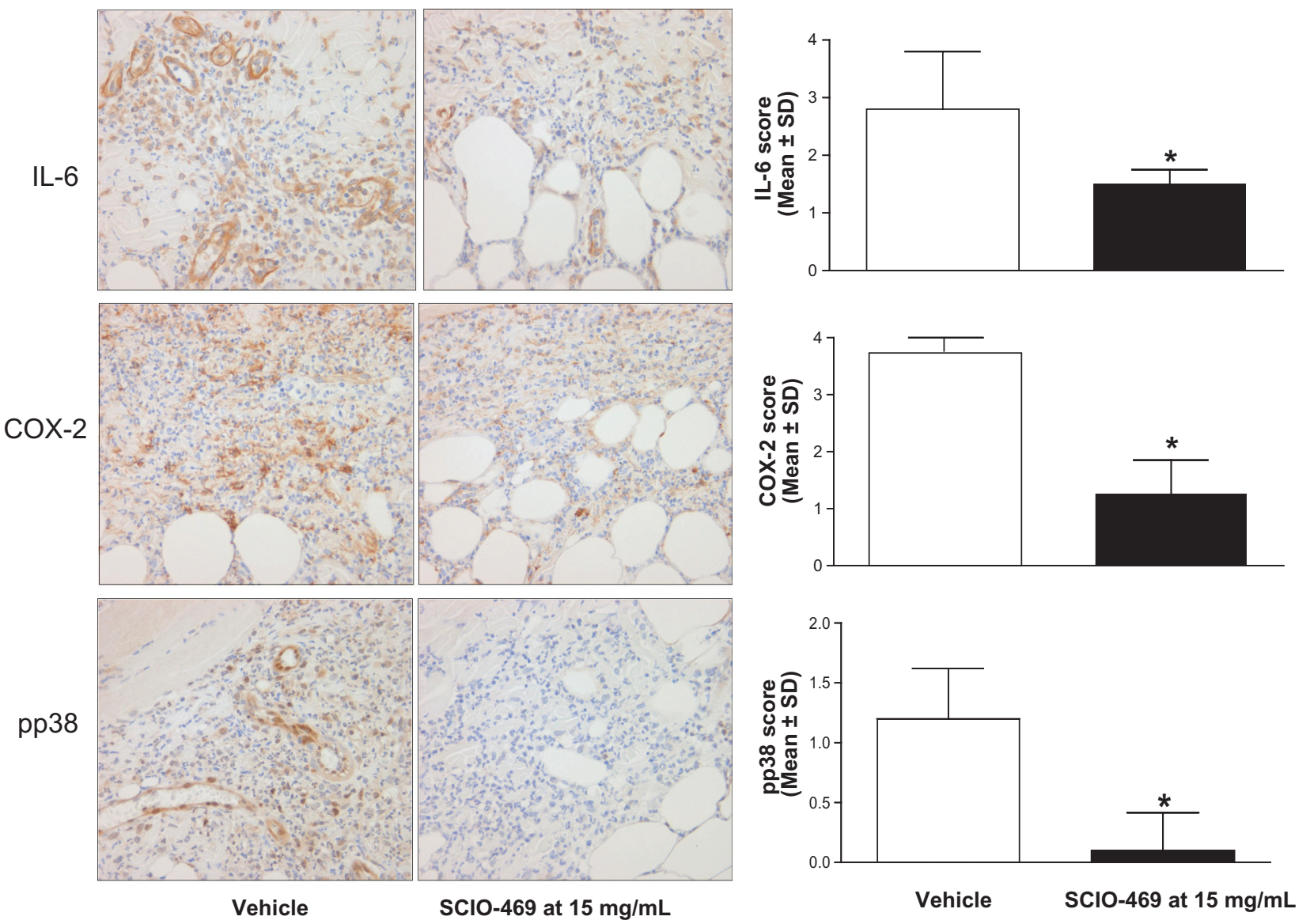

Figure 3 SCIO-469 significantly reduces IL-6, COX-2, and phophorylated p38 MAPK in the skin. Immunohistochemical studies revealed that SCIO-469 at a higher dose $(15 \mathrm{mg} / \mathrm{mL}$ ) significantly reduced IL-6 (upper panel; $* P<0.00 \mathrm{I}$ ), COX-2 (middle panel; $* P<0.00 \mathrm{I}$ ) and phosphorylated $\mathrm{p} 38 \mathrm{MAPK}$ (lower panel; $* P<0.00 \mathrm{I}$ ) expression in neutrophils and endothelial cells when compared to the vehicle group.

Notes: $400 \times$ magnification. Values are reported as the mean $\pm S D ; n=10$.

Abbreviations: COX-2, cyclooxygenase-2; IL, interleukin; MAPK, mitogen-activated protein kinase; SD, standard deviation.

reduce neutrophil driven acute skin inflammation. These results suggests that $\alpha$-selective $\mathrm{p} 38$ MAPK inhibition may be an effective therapeutic strategy to manage acute skin inflammation.

\section{Disclosures}

The authors report no conflicts of interest in this work.

\section{References}

1. Roosterman D, Goerge T, Schneider SW, Bunnett NW, Steinhoff M. Neuronal control of skin function: the skin as a neuroimmunoendocrine organ. Physiol Rev. 2006;86:1309-1379.

2. Beissert S, Cavazzana I, Mascia F, et al. Mechanisms of immunemediated skin diseases: an overview. Clin Exp Rheumatol. 2006; $24: 1-6$.

3. Lebwohl M. A clinician's paradigm in the treatment of psoriasis. J Am Acad Dermatol. 2005;53:59-69.

4. Heyer G, Koppert W, Martus P, Handwerker HO. Histamine and cutaneous nociception: histamine-induced responses in patients with atopic eczema, psoriasis and urticaria. Acta Derm Venereol. 1998;78: $123-126$

5. Zelickson BD, Muller SA. Generalized pustular psoriasis. A review of 63 cases. Arch Dermatol. 1991;127:1339-1345.
6. Terui T, Ozawa M, Tagami H. Role of neutrophils in induction of acute inflammation in T-cell mediated immune dermatosis, psoriasis: a neutrophilassociated inflammation-boosting loop. Exp Dermatol. 2000;9:1-10.

7. Tay YK, Tham SN. The profile and outcome of pustular psoriasis in Singapore: a report of 28 cases. Int J Dermatol. 1997;36:266-271.

8. Langtry JA, Carr MM, Ive FA, Gordon P, Hunter JA, Harper JI. Ichthyosiform erythroderma associated with generalized pustulosis. Br J Dermatol. 1998;138:502-505.

9. Hildesheim J, Awad RT, Fornace AJ. p38 mitogen-activated protein kinase inhibitor protects the epidermis against the acute damaging effects of ultraviolet irradiation by blocking apoptosis and inflammatory response. J Invest Dermatol. 2004;122:497-502.

10. Takanami-Ohnishi Y, Amano S, Kimura S, et al. Essential role of p38 mitogen activate protein kinase in contact hypersensitivity. J Biol Chem. 2002;277:37896-37903.

11. Kim AL, Labasi JM, Zhu Y, et al. Role of p38 MAPK in UVB-induced inflammatory responses in the skin of SKH-1 hairless mice. J Invest Dermatol. 2005;124:1318-1325.

12. Ipaktchi K, Mattar A, Niederbichler AD, et al. Topical p38 MAPK inhibition reduces dermal inflammation and epithelial apoptosis in burn wounds. Shock. 2006;26:201-209.

13. Ottosen ER, Sorensen MD, Bjorkling F, et al. Synthesis and structureactivity relationship of aminobenzophenones. A novel class of p38 MAPK kinase inhibitors with high anti-inflammatory activity. $J \mathrm{Med}$ Chem. 2003;46:5651-5662. 
14. Valiveti S, Hammell DC, Farles DC, Stinchcomb AL. In vitro/in vivo correlation studies for transdermal delta 8-THC development. J Pharm Sci. 2004;93:1154-1164.

15. Aronson PJ. A review of the role of neutrophils in psoriasis and related disorders. Dermatol Online J. 2008;14:7.

16. Cruz MT, Duarte CB, Goncalo M, Carvalho AP, Lopes MC. Involvement of JAK2 and MAPK on type II nitric oxide synthaase expression in skin-derived dendritic cells. Am J Physiol. 1999;277: 1050-1057.

17. Bochkov VN, Kadl A, Huber J, Gruber F, Binder BR, Leitinger N. Protective role of phospholipids oxidation products in endotoxininduced tissue damage. Nature. 2002;419:77-81.

18. Marleau S, Laclos FB, Sanchez AB, Poubelle PE, Borgeat P, Marleau S. Role of 5-lipoxygenase products in the local accumulation of neutrophils in dermal inflammation in the rabbit. J Immunol. 1999;163:3449-3458.

19. Kim H, Koh G. Lipopolysaccharide activates matrix metalloproteinase-2 in endothelial cells through an NF-kappaB-dependent pathway. Biochem Biophys Res Commun. 2000;269:401-405.

20. Landmann R, Scherer F, Schumann R, Link S, Sansano S, Zimmerli W. LPS directly induces oxygen radical production in human monocytes via LPS binding protein and CD14. J Leukoc Biol. 1995;57:440-449.

21. Frey EA, Finlay BB. Lipopolysaccharide induces apoptosis in a bovine endothelial cell line via a soluble CD14 dependent pathway. Microb Pathog. 1998;24:101-110.

22. Dominquez C, Powers DA, Tamayo NO. p38 MAP kinase inhibitors: many are made, but few are chosen. Curr Opin Drug Discoy Devel. 2005;4:421-430.

23. Cottrell J, Meyenhofer, Medicherla S, Higgings LS, O'Connor JP. Analgesic effects of p38 kinase inhibitor treatment on bone fracture healing. Pain. 2009;142:116-126.
24. Medicherla S, Protter AA, Ma JY, et al. Preventive andterapeutical potential of $\mathrm{p} 38$ alpha-selective mitogen-activated protein kinase inhibitor in nonobese diabetic mice with type 1 diabetes. J Pharmacol Exp Ther. 2006;318:99-107.

25. Medicherla S, Ma JY, Mangadu R, et al. A selective p38 alpha mitogen activated protein kinase inhibitor reverses cartilage and bone destruction in mice with collagen induced arthritis. J Pharmacol Exptl Ther. 2006;318:132-141.

26. Kumar S, McDonnell PC, Gum RJ, Hand AT. Novel homologues of $\mathrm{CSBP} / \mathrm{p} 38 \mathrm{MAP}$ kinase: activation, substrate specificity and sensitivity to inhibition by pyridinyl imidazoles. Biochem Biophys Res Commun. 1997;235:533-538.

27. Richards HL, Ray DW, Kirby B, et al. Response of the hypothalamicpituitary-adrenal axis to psychological stress in patients with psoriasis. Br J Dermatol. 2005;153:1114-1120.

28. Herlin T, Kragballe K. Enhanced monocyte and neutrophil cytotoxicity and normal cyclic nucleotide levels in severe psoriasis. Br J Dermatol. 1981;105:405-413.

29. Ikoma A, Fartasch M, Heyer G, Miyachi Y, Handwerker HO, Schmelz M. Painful stimuli evoke itch in patients with chronic pruritus; central sensitizatioin for itch. Neurology. 2004;62:212-217.

30. Sweitzer SM, Peters MC, Ma JY, et al. Peripheral and central p38 MAPK mediates capsaicin induced hyperalgesia. Pain. 2004;111:278-285.

31. Funding AT, Johansen C, Kragballe K, et al. Mitogen- and stressactivated protein kinase 1 is activated in lesional epidermis and regulates the expression of proinflammatory cytokines. J Invest Dermatol. 2006;126:1784-1791.
Journal of Inflammation Research

\section{Publish your work in this journal}

The Journal of Inflammation Research is an international, peer-reviewed open-access journal that welcomes laboratory and clinical findings on the molecular basis, cell biology and pharmacology of inflammation including original research, reviews, symposium reports, hypothesis formation and commentaries on: acute/chronic inflammation; mediators of inflamma-

\section{Dovepress}

tion; cellular processes; molecular mechanisms; pharmacology and novel anti-inflammatory drugs; clinical conditions involving inflammation. The manuscript management system is completely online and includes a very quick and fair peer-review system. Visit http://www.dovepress.com/ testimonials.php to read real quotes from published authors. 